\title{
Sorption and Solubility of Nanofilled Composite Resins in Mouthwashes with Different pH
}

\section{Shaqran Hamid Alabbadi ${ }^{1}$, Meshal Abdullah Bagari ${ }^{1}$, Ibrahim Mohamed Hamouda ${ }^{2 *}$ and Khalid Talal Abdullah Aboalshamat ${ }^{3}$}

${ }^{1}$ Interns, College of Dentistry, Umm Alqurra University, Makkah, Saudi Arabia

${ }^{2}$ Professor of Dental Biomaterials, College of Dentistry, Umm Alqurra University,

Makkah, Saudi Arabia

${ }^{3}$ Assistant Professor of Dental Public Health, College of Dentistry, Umm Alqurra

University, Makkah, Saudi Arabia

*Corresponding Author: Ibrahim Mohamed Hamouda, Professor of Dental

Biomaterials, College of Dentistry, Umm Alqurra University, Makkah, Saudi Arabia.
Received: May 26, 2020

Published: June 24, 2020

(C) All rights are reserved by Ibrahim

Mohamed Hamouda., et al.

\begin{abstract}
Objectives: The aim of this study was test the effect of mouthwashes with different $\mathrm{pH}$ on sorption and solubility of nano-filled composite resin restorative materials.

Materials and Methods: 56 cylindrical specimens were prepared from 2 types of nanofilled composite resins, 28 specimens from each material. Specimens of each type of composite were randomly divided into four groups ( $\mathrm{n}=7$ ). 7 specimens were used as a control group immersed in distilled water. The other 3 groups were stored in the following mouth washes (Avohex, Listerine and Parodontax) for seven days. Specimens were dried in desiccator to a constant weight before immersion. The immersion media were changed daily for 7 days, waived in air and weighted to calculate the amount of sorption. Specimens were dried again and reweighted to calculate the amount of solubility. Sorption and solubility tests were made using electronic balance.

Results: Both composite resins showed varying degrees of water sorption and solubility in all storage media. SDI ice composite resin showed higher water sorption in Listerine and lower in Avohex mouth washes. SDI Ice nanohybrid composite resin showed higher solubility in Avohex mouth wash and lower solubility in distilled water. Charisma nanohybrid composite resin showed higher water sorption in Avohex mouth wash and lower in distilled water. Listerine and Parodontax mouthwashes showed intermediate comparable values. Charisma nanohybrid composite resin showed higher solubility in distilled water and lower in Listerine mouthwash. Listerine and Parodontax mouth washes had intermediate effects of sorption and solubility on both types of composite resins.

Conclusion: All tested nanofilled composite resins showed varying degrees of water sorption and solubility in all storage media. SDI ice composite resin showed higher water sorption in Listerine and higher solubility in Avohex mouthwashes. It exhibited lower sorption in Avohex mouth wash and lower solubility in distilled water. Charisma nanohybrid composite resin composite resin showed higher water sorption in Avohex and higher solubility in distilled water. It demonstrated lower sorption in distilled water and lower solubility in Avohex mouth wash.
\end{abstract}

Keywords: Nanofilled; Composite Resins; Restorative Materials; Water Sorption and Solubility

\section{Introduction}

Resin composites are largely used for building up anterior and posterior restorations due to their excessive esthetic quality and improved physical and mechanical properties [1]; recent dental composite resins possess superior physical and mechanical properties due to the introduction of the nanotechnology in dental biomaterials. Nanocomposite resins have many advantages such as high surface quality and improved physical properties. There are different oral factors such as continuous changes in the oral $\mathrm{pH}$ and temperature can influence the surface properties of dental tissues and restorations [2].

Typically a dental composite resins composed of a resin matrix from a modified methacrylate or acrylate. The most commonly used methacrylate matrix is Bisphenol A-glycidyl methacrylate (Bis-GMA) and urethane dimethacrylate (UDMA), in addition to tri-ethylene glycol dimethacrylate (TEGMA). TEGMA is added as 
a comonomer to regulate the viscosity of the resin matrix, since Bis-GMA has high molecular weight with high viscosity. Reduction of viscosity improves the handling characteristics. Inorganic fillers such as silica, quartz or glasses are added to reduce the polymerization shrinkage and to increases the radio-opacity of the composite resin. Also, the filler modify the translucency of the restoration, which can be helpful in the diagnosis of dental caries through dental restoration [3].

There were many classes of composite resins such as: (1) macro-filled composite resins with fillers of particle size ranging from 5 - $10 \mu \mathrm{m}$. Final restorations with this type of composite resin were difficult to polish, leaving rough surface and plaque retention. (2) Micro-filled composite resins which have fillers of particle size of $0.4 \mu \mathrm{m}$. Micro-fillers are made from colloidal silica. Compared with macro-filled, resin with this filler size produces shiny smooth surface and less plaque retention. However, its mechanical properties are compromised as the filler load decreases as compared to traditional ones (40 - 45 per cent by weight). (3) Hybrid filler composite resins which have fillers of particle sizes ranging from $0.4 \mu \mathrm{m}$ and $5 \mu \mathrm{m}$. This type of composite was designed to combine the advantages of the macro-filled and micro-filled composite resins. Hybrid filler resins have high thermal expansion and increased mechanical strength. Also, it has reduced polymerization shrinkage due to the combined types of filles. (4) Nano-filled composite resins have fillers of particle size between $20-70 \mathrm{~nm}$. Nanoparticles make up restorations of nano-cluster which function as a single unit. These have a high mechanical strength comparable to hybrid material, high resistance to wear and are good polish ability [4].

Restorative composite resins are widely used in dentistry due to their cosmetic properties and adhesion ability to the teeth. Composite resins are designed to be used for restoration of anterior and posterior teeth [5]. Composite resin restorations can be colored easily to accommodate the wide variety of teeth colors, also they can match the colors of each tooth segments. Also, the composite restorations exhibits acceptable bond strengths to tooth structure, less cost and more conservative alternative to dental crowns. Composite resin restorations can be used to repair chipped, broken or worn teeth. The damage may be easily repaired by adding additional composite resin materials. Unlike metallic restorations, resin composites does not corrode at all [6]. The most important disadvantage of composite resin restorations is the shrinkage that occurred during manipulation leading to microleakage, which can cause recurrent caries [7]. Composite resin restorations not similar amalgam fillings in resistance of the chewing stresses [8]. The prepared tooth should be completely dry for better restorationtooth bonding [9].
The most recent composite resins restorative materials are the nano-filled composites that contain fillers of particle size in a nano-metric dimensions [10]. Nanoparticles filled composites have a large surface area that provide greater interfacial region for bonding with the resin matrix [11]. It is believed that nano-filled composite resins have good polish-ability, smooth surface quality and less plaque retention but has low wear resistance. It have acceptable mechanical behavior and excellent finish, improved optical properties and minimized polymerization shrinkage [12].

Water sorption is the spread of water into and onto the surface of the composite resin materials. Water sorption could results in chemical degradation of the restoration leading to several drawbacks such as debonding of the fillers from the polymer matrix and releasing of the residual unreacted monomers [13]. Water sorption and solubility can affect the mechanical strength, color stability and abrasion resistance of the resin composite [14]. Furthermore, resin composite have shown reduce strength and longevity as a result of excessive water sorption and solubility $[15,16]$. The resin composite polymer community will soak up a certain amount of water and launch monomer and ion to the encompassing surroundings. The water absorbed and consequent hygroscopic growth of composite may compensate for the polymerization shrinkage $[17,18]$.

Nowadays, mouth rinses are extensively used to resist caries and periodontal diseases. Frequently use of mouth rinses may additionally have detrimental outcomes on oral tissues and at the restorations inside the oral cavity [1]. Mouthwashes are usually recommended to minimize halitosis and periodontal problems [19]. Although mouthwashes are effective in reducing plaque causing gingivitis and in providing fluoride to prevent dental caries, several studies have discussed the risks associated with the routine use of mouthwashes. Such threats include dry mouth [20], increased occurrence of cancer of the head and neck [21], extrinsic pigmentation [20] and increased degradation of resin composite [22]. The effect of different types of mouth rinses with different $\mathrm{pH}$ on the nano-filled composite resins will be evaluated.

\section{Materials and Methods}

The materials used in this study are presented in table 1 . Two types of composite resins were used (SDI ice nanohybrid composite and Charisma nanohybrid composite). Three different mouthwashes were used, these mouthwashes were routinely used for oral hygiene, without alcohol (Avohex, Listerine zero and Parodontax). The $\mathrm{Ph}$ of each mouth rinse was measured using $\mathrm{Ph}$ meter. The $\mathrm{Ph}$ for distilled water was 5.7, Listerine mouth wash was 4.9, Parodontax mouth wash was 6.7 and Avohex mouth wash 5.6. 


\begin{tabular}{|c|c|c|}
\hline Materials & Company name & Active ingredients \\
\hline Avalon Avohex mouthwash & Avalon pharma, Saudi Arabia & Chlorhexidine gluconate \\
\hline Listerine Zero mouthwash & Johnson and Johnson company, Untied state & $\begin{array}{c}\text { Aqua, propylene, glycol, sorbitol, polox- } \\
\text { amer, sodium lauryl sulfate }\end{array}$ \\
\hline Parodontax mouthwash & GlaxoSmithKline (GSK), Untied state \\
\hline $\begin{array}{c}\text { SDI ice Nanohybrid composite } \\
\text { resin }\end{array}$ & $\begin{array}{c}\text { SDI Germany GmbH, Hansestrasse 8551149 } \\
\text { Cologne, Germany }\end{array}$ & $\begin{array}{c}\text { Multifunctional methacrylate ester, inor- } \\
\text { ganic nano-hybrid filler }\end{array}$ \\
\hline $\begin{array}{c}\text { Charisma Nanohybrid composite } \\
\text { resin }\end{array}$ & Kulzer GmbH, Germany & \begin{tabular}{c} 
TCD-DI-HEA matrix, nano-hybrid filler \\
\hline
\end{tabular} \\
\hline
\end{tabular}

Table 1: Shows the materials used.

56 cylindrical specimens were prepared from both types of nanofilled composite resins, 28 specimens from each material. The specimens were prepared using a stainless steel mold of $15 \mathrm{~mm}$ diameter and $1.5 \mathrm{~mm}$ thickness (Figure 1). The composite resin paste was inserted in stainless steel molds in one increment and was covered with celluloid strip. The material was pressed into the molds using glass slide. The glass slide was removed and the composite resin material was cured for 40 seconds through the celluloid matrix in place using a conventional light curing unit (Optilux 400 , Demetron research agency, Danbury, CT, USA) according to the manufacturer's instructions with light output (480 $\left.\pm 32 \mathrm{~mW} / \mathrm{cm}^{2}\right)$.

After curing of the specimens, they were removed from their molds and finished to remove excesses. Specimens of each type of composite resin were randomly divided into four groups $(n=7) .7$ specimens were used as a control group immersed in distilled water. The other groups were stored in three different mouth washes with different $\mathrm{pH}$. All specimens were placed in a desiccator at $37^{\circ} \mathrm{C}$ for 24 hours, stored in another desiccator at $23^{\circ} \mathrm{C}$ and weighted to an accuracy of $\pm 0.1 \mathrm{mg}$ using an AW220M (Shimadzu Corporation, Japan) electronic balance. This cycle was repeated until a constant weight was obtained(M1). The control group specimens were immersed in distilled water at $37^{\circ} \mathrm{C}$. The other groups were immersed in the corresponding mouth washes at $37^{\circ} \mathrm{C}$. The storage medium was changed every day. At the end of 7 days of storage, the specimens were removed waved in air and weighted to obtain the amount of water sorption(M2). Each specimen was dried, desiccated again to calculate the amount of water solubility (M3).

The amount of water sorption (Wsp) and water solubility (Wsl) values $\left(\mu \mathrm{g} / \mathrm{mm}^{3}\right)$ were calculated with the following formulas:

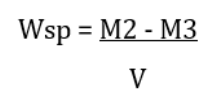

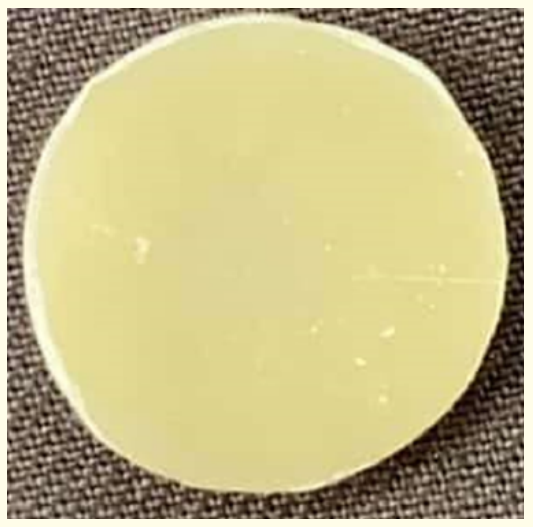

Figure 1: Prepared composite resin specimen.

Where: "Wsp" is the water sorption; "Wsl" is the water solubility; "M1" is the specimen's weight before immersion in water; "M2" is the specimen's weight after immersion in the storage medium; "M3" is the specimen's weight after being kept in desiccator until constant weight; "V" is the specimen' s volume [23].

\section{Statistical analysis}

The results were collected, tabulated and exposed to 1-way ANOVA to detect the significant differences among the tested groups. Then, LSD test was conducted to demonstrate the significant difference between the tested groups. The level of significance was at $\mathrm{p} \leq 0.05$.

\section{Results}

The results of sorption of both types of composite resins are presented in tables 2 and 3. Both types of composite resins showed varying degrees of water sorption and solubility in all storage media. The statistical analysis of the results indicated that there were significant differences in sorption of SDI Ice nanohybride composite resin in Listerine and Parodontax mouth washes when compared 


\begin{tabular}{|c|c|c|c|c|}
\hline Storage media & ph & Mean \pm SD & F-value & p-value \\
\hline Distilled water & 5.7 & $59.861^{\mathrm{B}} \pm 10.3$ & & \\
\cline { 1 - 3 } Listerine mouth wash & 4.9 & $82.511^{\mathrm{A}} \pm 23.1$ & \multirow{2}{*}{15.01} & \multirow{2}{*}{$\mathrm{p} \leq 0.001$} \\
\cline { 1 - 3 } Parodontax mouth wash & 6.7 & $81.703^{\mathrm{A}} \pm 13.8$ & & \\
\cline { 1 - 3 } Avohex mouth wash & 5.6 & $33.976 \pm 12.2$ & & \\
\hline
\end{tabular}

Means with different superscripted letters are significantly different.

Table 2: Water sorption $(\mu \mathrm{g})$ of SDI Ice nanohybride composite resin in deferent mouth washes with different ph.

\begin{tabular}{|l|l|l|l|l|}
\hline \multicolumn{1}{|c|}{ Storage media } & \multicolumn{1}{|c|}{ ph } & \multicolumn{1}{c|}{ Mean \pm SD } & F-value & \multicolumn{1}{c|}{ p-value } \\
\cline { 1 - 3 } Distilled water & 5.7 & $46.109^{\mathrm{C}} \pm 13.6$ & 3.119 & $\mathrm{p} \leq 0.05$ \\
\cline { 1 - 3 } Listerine mouth wash & 4.9 & $64.715^{\mathrm{B}} \pm 12.6$ & & \\
\cline { 1 - 3 } Parodontax mouth wash & 6.7 & $63.905^{\mathrm{B}} \pm 20.3$ & & \\
\cline { 1 - 3 } Avoh mouth wash & 5.6 & $72.804^{\mathrm{A}} \pm 19.4$ & & \\
\cline { 1 - 3 }
\end{tabular}

Means with different superscripted letters are significantly different.

Table 3: Water sorption $(\mu \mathrm{g})$ of Charisma nanohybride composite resin in deferent mouth washes with different ph.

to distilled water and Avohex mouth wash ( $\mathrm{p} \leq 0.001)$ (Table 1). There were significant differences in sorption of Charisma nanohybride composite resin in Avohex mouth wash and distilled water when compared to the other mouth washes ( $\mathrm{p} 0.05$ ) (Table 2). SDI ice composite resin showed greater water sorption in Listerine mouth wash and lower sorption in Avohex mouth wash. Charisma nanohybrid composite resin had greater water sorption in Avohex mouth wash and less sorption in distilled water.

The results of solubility of both types of composite resins are presented in tables 4 and 5. The statistical analysis of the results indicated that there was a significant difference in solubility of SDI Ice nanohybride composite resin $(p \leq 0.001)$. There was a significant difference in solubility of Charisma nanohybride composite resin $(p \geq 0.05)$. SDI Ice nanohybrid composite resin showed greatest solubility in Avohex mouth wash and less solubility in distilled water. Listerine and Parodontax mouthwashes showed intermediate comparable values. Charisma nanohybrid composite resin showed greater solubility in distilled water and less solubility in Listerine mouth wash. Parodontax and Avohex mouth washes showed comparable water solubility values.

\section{Discussion}

The solubility behavior of composite resin materials is affected by the organic matrix and filler type. Regarding the water solubility, negative values were obtained, that varied throughout the entire period of immersion; the solubility is masked by the higher values of water sorption [24].

\begin{tabular}{|l|c|l|l|l|}
\hline \multicolumn{1}{|c|}{ Storage media } & ph & \multicolumn{1}{|c|}{ Mean \pm SD } & F-value & p-value \\
\cline { 1 - 3 } Distilled water & 5.7 & $12.134^{\mathrm{D}} \pm 8.3$ & 26.3 & $\mathrm{p} \leq$ \\
\cline { 1 - 3 } Listerine mouth wash & 4.9 & $28.313^{\mathrm{B}} \pm 20.4$ & & 0.001 \\
\cline { 1 - 3 } $\begin{array}{l}\text { Parodontax mouth } \\
\text { wash }\end{array}$ & 6.7 & $\begin{array}{l}16.1790^{\mathrm{CD}} \pm \\
12.4\end{array}$ & & \\
\cline { 1 - 3 } Avohex mouth wash & 5.6 & $70.377^{\mathrm{A}} \pm 10.7$ & & \\
\hline
\end{tabular}

Means with different superscripted letters are significantly different.

Table 4: Water solubility $(\mu \mathrm{g})$ of SDI Ice nanohybride composite resin in deferent mouth washes with different ph.

\begin{tabular}{|l|c|c|c|c|}
\hline \multicolumn{1}{|c|}{ Storage media } & ph & \multicolumn{1}{|c|}{ Mean \pm SD } & F-value & p-value \\
\hline Distilled water & 5.7 & $16.988^{\mathrm{A}} \pm 4.8$ & 0.767 & $\mathrm{p} \leq 0.05$ \\
\cline { 1 - 3 } Listerine mouth wash & 4.9 & $8.899^{\mathrm{C}} \pm 1.7$ & & \\
\cline { 1 - 3 } $\begin{array}{l}\text { Parodontax mouth } \\
\text { wash }\end{array}$ & 6.7 & $12.134^{\mathrm{B}} \pm 4.9$ & & \\
\cline { 1 - 3 } Avohex mouth wash & 5.6 & $70.377^{\mathrm{A}} \pm 10.7$ & & \\
\hline
\end{tabular}

Means with different superscripted letters are significantly different.

Table 5: Water solubility ( $\mu \mathrm{g}$ ) of Charisma nanohybride composite resin in deferent mouth washes with different ph. 
The composition of the composite resins can interfere with the resistance to the action of chemicals, which may make the materials more or less susceptible to softening and degradation. The uniform distribution of filler particles in the resin matrix is important for the performance of this material in humid environments as bubbles and voids at the filler/matrix interface can increase the amount of water absorption by the composite resin [25]. Clinically, the effects of mouthwashes on the restorative material may be different. Clinical studies provide more accurate results as in vitro studies do not consider certain variables, such as natural saliva, food, drinks and the $\mathrm{pH}$ of the oral environment [1].

ADA Specification No. 2713 requires that, the water sorption of all materials be less than or equal to $40 \mu \mathrm{g} / \mathrm{mm}^{3}$ and the solubility of all materials be less than or equal to $7.5 \mu \mathrm{g} / \mathrm{mm}^{3}$ within a seven day period of water storage. On the same time, resin composites indicated as restorative materials must also comply with ISO 4049:1988 for a maximum value of $40 \mu \mathrm{g} / \mathrm{mm}^{3}$ for water sorption and $7.5 \mu \mathrm{g} / \mathrm{mm}^{3}$ for water solubility within a seven-day period of water storage. It appears from the results of solubility that all the tested composite materials in this study pass these two standards $[26,27]$.

The results of this study indicated that, all the composites being tested in this study exhibited sorption values were greater than the standard limits of the ADA Specification No. 2713 and ISO 4049:1988. These results indicated that, the used mouth washes were more aggressive to the tested composite materials. Also, it was noted that Avohex mouth wash causes bleaching to the composite resins specimens (Figure 2). Other study indicated that, the sorption and solubility properties of the composite resins were more altered by mouthwashes than the surface hardness [27]. A previous study showed water sorption and solubility values were less than the ADA and ISO requirements [28].

The results of the present study showed that SDI Ice composite resin exhibited excessive water sorption with listerine and less with Avohex mouth washes. On the other hand, Charisma composite resin showed excessive water sorption in Avohex mouth wash greater than the other storage media. Avohex mouth wash caused excessive solubility to SDI Ice composite resin and intermediate values were noted with Charisma composite resin.

Previous study [29], concluded that the overall sorption of nanofilled composite resins was higher in alcohol-based mouth-

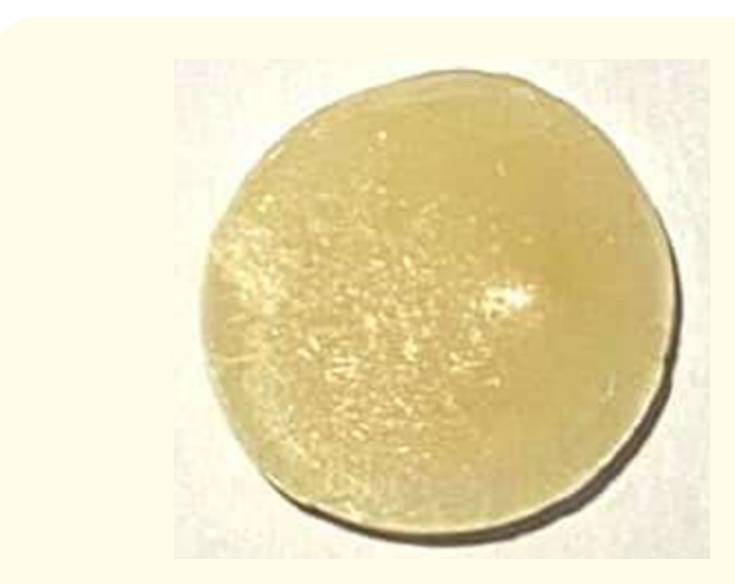

Figure 2: Bleached specimen after immersion in Avohex mouth wash

washes. Such mouthwashes could cause softening of composite resin surfaces which leads to leaching out of monomers. Removal of monomers from the polymer structure leads to opening of the polymer chains which causes diffusion of water inside the composite fillings. This diffusion of process enhances water sorption [30]. The sorption values of the hybrid composite resins were found to be lower than that of the nanofilled composite when the hybrid composites were subjected to mouthwashes that contain alcohol [29].

\section{Conclusion}

The following conclusions were obtained:

1. Both composite resins showed varying degrees of water sorption and solubility in all storage media.

2. SDI ice composite resin showed higher water sorption in Listerine and higher solubility in Avohex mouthwashes. It exhibited lower sorption in Avohex mouth wash and lower solubility in distilled water.

3. Charisma nanohybrid composite resin composite resin showed higher water sorption in Avohex and higher solubility in distilled water. It demonstrated lower sorption in distilled water and lower solubility in Avohex mouth wash.

4. Listerine and Parodontax mouth washes had intermediate effects of sorption and solubility on both types of composite resins. 


\section{Bibliography}

1. Almeida GS., et al. "The effect of mouthrinses on salivary sorption, solubility and surface degradation on a nanofilled and a hybrid resin composite". Journal of Conservative Dentistry 35 (2010): 105-111.

2. Affan Ahmad., et al. "Effect of different chlorhexidine based mouthwashes on hardness of resin based dental composites. An in-vitro study". Journal of Khyber College of Dentistry 4 (2014): 2.

3. McCabe F. "Applied Dental Materials". Blackwell Publishing Ltd. (2008): 197-198.

4. Bonsor J Stephen. "A clinical guide to applied dental materials". Pearson, Gavin J Amsterdam: Elsevier/Churchill Livingstone (2013): 73-75.

5. Mitra SB., et al. "An application of nanotechnology in advanced dental materials". The Journal of the American Dental Association 134 (2003): 1382-1390.

6. Bjørklund G. "Mercury in the dental office. Risk evaluation of the occupational environment in dental care (in Norwegian)". Tidsskr Nor Laegeforen 111 (1991): 948-951.

7. Bernardo Mario. "Survival and reasons for failure of amalgam versus composite posterior restorations placed in a randomized clinical trial". Journal of the American Dental Association (2013): 779.

8. Shenoy A. "Is it the end of the road for dental amalgam? A critical review". Journal of Conservative Dentistry 11 (2008): 99107.

9. Heintze SD and Rousson V. "Clinical effectiveness of direct class II restorations - a meta-analysis". The Journal of Adhesive Dentistry 14 (2012): 407-431.

10. Schadler LS., et al. "Polymer nanocomposites: A small part of the story". Journal of Management 59 (2007): 53-60.

11. Ash BJ., et al. "Glass Transition Temperature Behavior of Alumina/PMMA Nanocomposites". Journal of Polymer Science 42 (2004): 4371-4383.

12. Bahadur S and Schwartz CJ. "The influence of nanoparticle fillers in polymer matrices on the formation and stability of transfer film during wear". Tribol Interf Eng Ser 55 (2008): 1734.
13. Emami N., et al. "Effect of light power density variations on bulk curing properties of dental composites". Journal of Dentistry 31 (2003): 189-196.

14. Shintani H., et al. "Water sorption, solubility and staining properties of microfilled resins polished by various method". Dental Materials 4 (1985): 54.

15. Sideridou I., et al. "Study of water sorption, solubility and modulus of elasticity of light-cured dimethacrylate-based dental resin". Biomaterials 24 (2003): 655-665.

16. Musanje L., et al. "Water sorption and mechanical behavior of cosmetic direct restorative materials in artificial saliva". Dental Materials 17 (2001): 394-401.

17. Robbins J. "Guidelines for the restoration of endodontically treated teeth". Journal of the American Dental Association 120 (1990): 558-658.

18. Goodacre CJ and Spolnik KJ. "The prosthodontic management of endodontically treated teeth a literature review. Part I. success and failure data, treatment concepts". Journal of Prosthodontics 3 (1994): 243-250.

19. Awliya WY. "The effect of mouthrinses on surface hardness and weight change of some esthetic restorative material". Journal of the Pakistan Dental Association 14 (2005): 84-89.

20. Kumar S., et al. "Effectiveness of a mouthrinse containing active ingredients in addition to chlorhexidine and triclosan compared with chlorhexidine and triclosan rinses on plaque, gingivitis, supragingival calculus and extrinsic staining". International Journal of Dental Hygiene 11 (2013): 35-40.

21. Eliot MN., et al. "Periodontal disease and mouthwash use are risk factors for head and neck squamous cell carcinoma". Cancer Causes and Control 24 (2013): 1315-1322.

22. Miranda DA., et al. "Effects of mouthrinse on Knoop hardness and surface roughness of dental composites after different immersion times". Brazilian Oral Research 25 (2011): 168-173.

23. International Standard Organisation. Dentistry-polymerbased filling, restorative and luting materials. ISO 4049, $3^{\text {rd }}$ edition (2000): 15-18.

24. Soancă A., et al. "Water Sorption and Solubility of an Experimental Dental Material: Comparative Study". Applied Medical Informatics 29 (2011): 27-33. 
25. De Moraes Porto IC., et al. "A Comparative Effect of Mouthwashes with Different Alcohol Concentrations on Surface Hardness, Sorption and Solubility of Composite Resins". Journal of Oral Health and Dental Management 13 (2014): 1-5.

26. "ADA division of science on behalf of the ADA council on scientific affairs: Resin-based composites". JADA 134.4 (2003): 510-513.

27. International Organization for Standardization. ISO4049: Dentistry polymer -based filling, restorative and lutingmaterials". Switzerland (2000).

28. Leal JP., et al. "Effect of mouth washes on solubility and sorption of restorative composite". International Journal of Dentistry (2017): 1-5.

29. Thirunavakarasu R and Nasim I. "Effect of mouthwashes on different composite resin - An in vitro study". Drug Invention Today 11 (2019): 1-5.

30. Asmussen E. "Softening of BISGMA-based polymers by ethanol and by organic acids of plaque". Scandinavian Journal of Dental Research 92 (1984): 257-261.

\section{Assets from publication with us}

- Prompt Acknowledgement after receiving the article

- Thorough Double blinded peer review

- Rapid Publication

- Issue of Publication Certificate

- High visibility of your Published work

Website: www.actascientific.com/

Submit Article: www.actascientific.com/submission.php

Email us: editor@actascientific.com

Contact us: +919182824667 